\title{
Applications of Nuclear Techniques, Computer Simulation and Microscopy to Surface Analysis of Materials
}

\author{
J. Pacheco de Carvalho****, C.F.R. Pacheco** and A.D. Reis ${ }^{* * * *}$ \\ *Departamento de Física, Universidade da Beira Interior, Rua Marquês d'Ávila e Bolama, 6201-001 Covilhã, \\ Portugal \\ **Unidade de Detecção Remota, Universidade da Beira Interior, Rua Marquês d'Ávila e Bolama, 6201-001 \\ Covilhã, Portugal
}

There is a wide range of surface analysis techniques which are, generally, complementary. Nuclear and nonnuclear techniques have been available. Nuclear techniques, which are non-destructive, provide for analysis over a few microns close to the surface of the sample, giving absolute values of concentrations of isotopes and elements. They have been applied in areas such as scientific, technologic, industry, arts and medicine, using $\mathrm{MeV}$ ion beams [1-7]. Nuclear reactions permit tracing of isotopes with high sensitivities. We use ion-ion nuclear reactions, elastic scattering and the energy analysis method where, at a chosen energy of the incident ion beam, an energy spectrum is recorded of ions from nuclear events, coming from several depths in the target. Such spectra are computationally predicted, giving target composition and concentration profile information [48]. A computer program has been developed in this context, mainly for flat targets [4-7]. The non-flat target situation arises as an extension. Successful applications of the method are given using the ${ }^{18} \mathrm{O}\left(\mathrm{p}, \mathrm{\alpha}_{0}\right){ }^{15} \mathrm{~N}$ reaction and elastic scattering of $\left({ }^{4} \mathrm{He}\right)^{+}$ions. SEM and TEM are used as useful complementary techniques.

Two types of samples were prepared containing thick and thin oxides, respectively. The first sample (S1) was obtained by high temperature oxidation of austenitic steel in $\mathrm{C}^{18} \mathrm{O}_{2}$ gas. Weight gain measurements had given a $4.2 \mu \mathrm{m}$ thick oxide. SEM has shown a reasonably flat oxide (Figure 1 (a)). The second sample (S2, also labelled $\mathrm{Al} / \mathrm{Al}_{2} \mathrm{O}_{3}$ ) was obtained by anodization of high purity aluminium at $100 \mathrm{~V}$ in an aqueous solution of ammonium citrate. An oxide thickness of $0.1370 \mu \mathrm{m}$ was expected. TEM has given an oxide film thickness of $0.1340 \mu \mathrm{m}$ (Figure $1(b))$. The ${ }^{18} \mathrm{O}\left(\mathrm{p}, \alpha_{0}\right){ }^{15} \mathrm{~N}$ reaction at $\mathrm{E}_{\mathrm{p}}=1.78 \mathrm{MeV}$ and $165^{\circ}$ was used to analyse sample S1. Figure 2 (a) shows a good computed fit to data. $\mathrm{A}^{18} \mathrm{O}$ step concentration profile was found, corresponding to a thick ${ }^{18} \mathrm{O}$ oxide with thickness $\mathrm{X}_{1}=4.4 \mu \mathrm{m}$. Sample $\mathrm{S} 2$ was analysed by elastic scattering of $\alpha$ particles at $\mathrm{E}_{\alpha}=2.0 \mathrm{MeV}$ and $165^{\circ}$. Figure 2 (b) shows a good computed fit to data. A thin oxide film thickness of $X_{1}=0.1350 \mu \mathrm{m}$ was found, close to the TEM value. The fit also shows a ratio of atomic densities of $\mathrm{O}$ and Al slightly above 1.5. The combined use of nuclear techniques, SEM and TEM microscopy has proved to be very important for surface analysis of materials. The reported results would be difficult to obtain by other techniques.

\section{References}

1. Tesmer J.R. and Nastasi M.A., eds. Handbook of Modern Ion Beam Materials Analysis. Pittsburgh, PA: Materials Research Society, 1995.

2. Amsel G. and Battistig G., Nucl. Instr. and Meth. B, 240:1, 2005.

3. Calvert J.M. et al., J. Phys. D Appl. Phys., 7:940, 1974.

4. Pacheco de Carvalho J.A.R., Ph D Thesis, University of Manchester, England, 1984.

5. Pacheco de Carvalho J.A.R. and Reis A.D., Nucl. Instr. and Meth. B, 266:2263, 2008.

6. Pacheco de Carvalho J.A.R. and Reis A.D., Bol. Soc. Esp. Ceram. V, 47:252, 2008.

7. Pacheco de Carvalho J.A.R., et al., Nucl. Instr. and Meth. B, 269:3054, 2011.

8. Barradas N.P. et al., Nucl. Instr. and Meth. B, 262:282, 2007. 


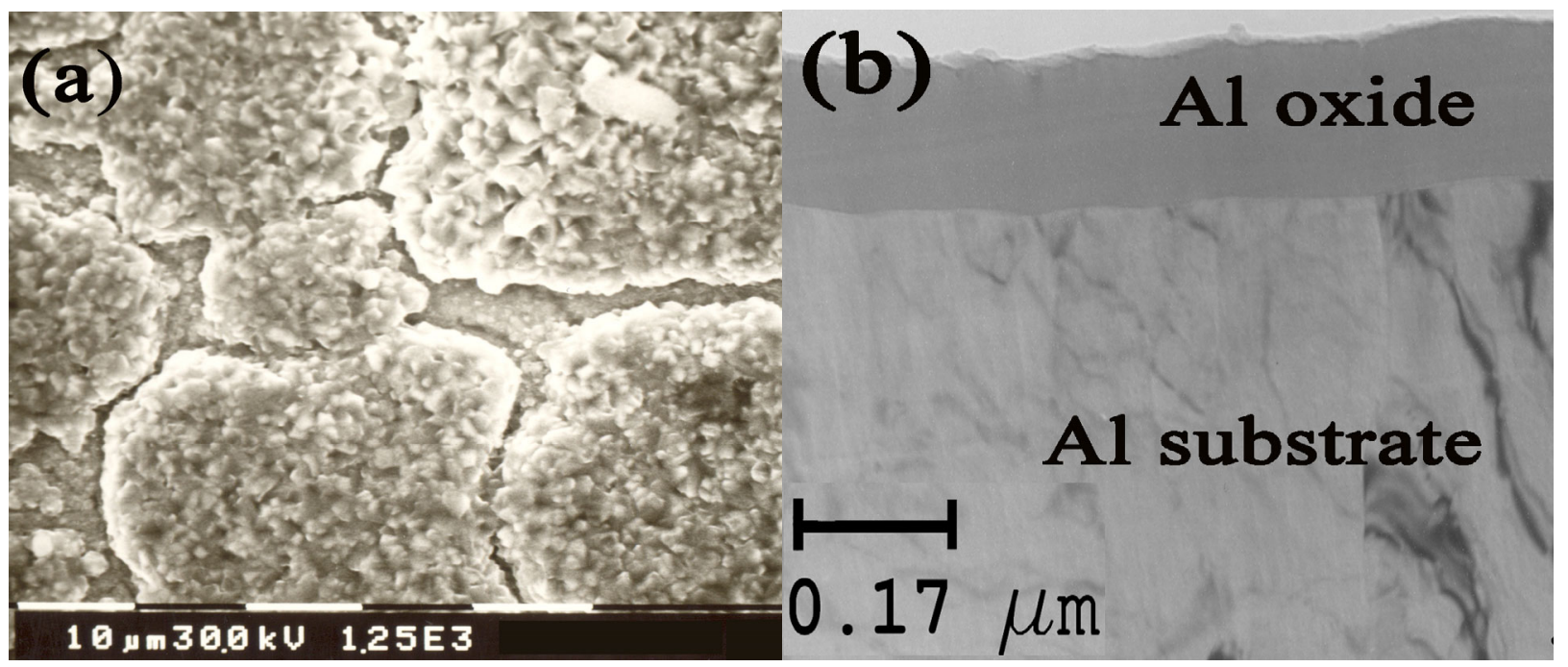

Figure 1. (a) SEM image of the thick oxide sample (S1). (b) TEM image of the $\mathrm{Al} / \mathrm{Al}_{2} \mathrm{O}_{3}$ sample (S2).
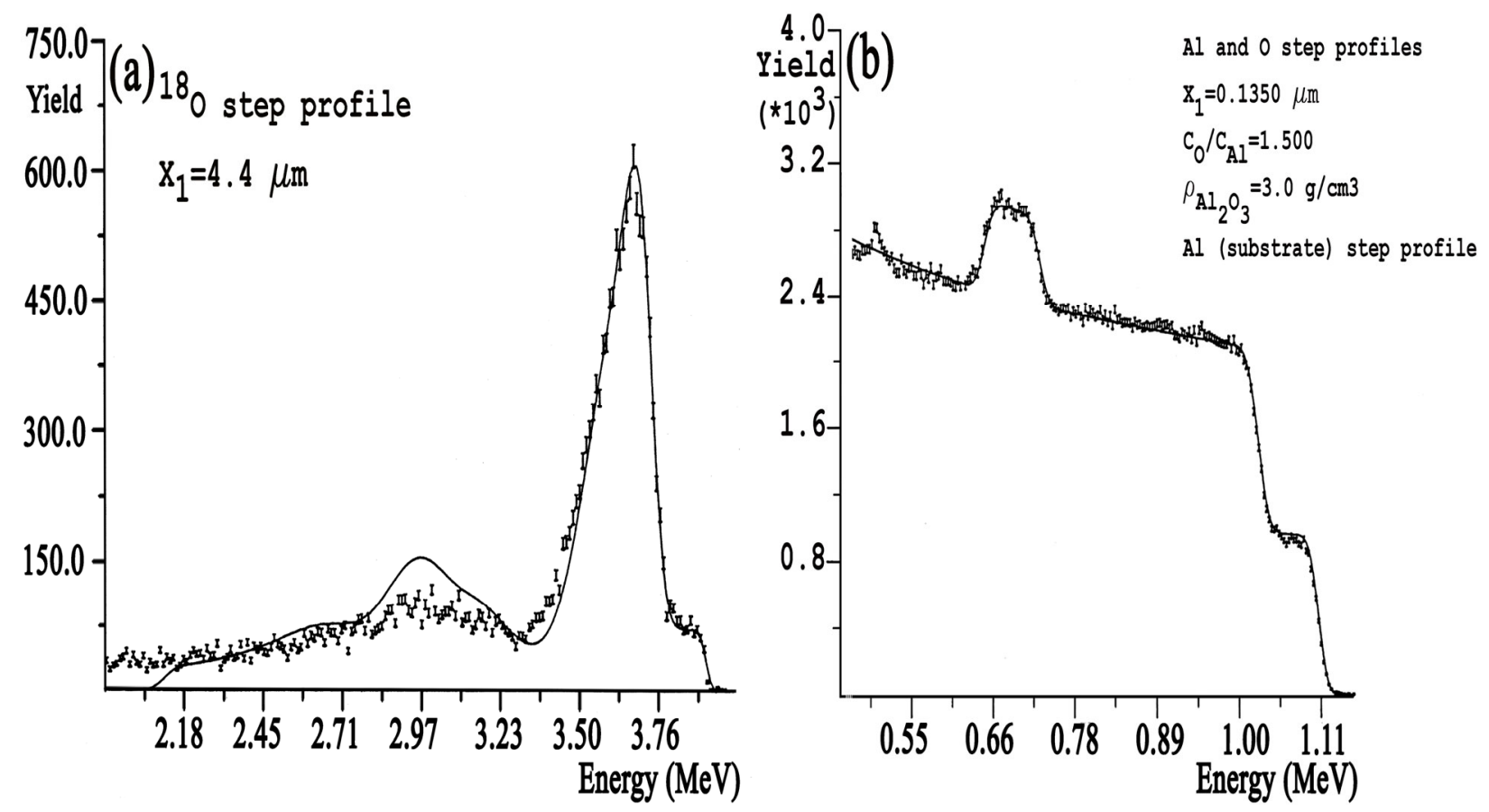

Figure 2. (a) Computed fit to the spectrum of the thick oxide sample (S1) at $\mathrm{E}_{\mathrm{p}}=1.78 \mathrm{MeV}, 165^{\circ}$. (b) Computed fit to the elastic scattering spectrum of the $\mathrm{Al} / \mathrm{Al}_{2} \mathrm{O}_{3}$ sample (S2) at $\mathrm{E}_{\alpha}=2.0 \mathrm{MeV}, 165^{\circ}$.

Supports from University of Beira Interior and FCT (Fundação para a Ciência e a Tecnologia)/PEstOE/FIS/UI0524/2011 (Projecto Estratégico-UI524-2011-2012) are acknowledged. 